\title{
The Research of Co-design Approaches Based on Designer Guidance in the Renovation of Old Community in Shanghai- Illustrated in the Case of Zhuyuan Community Center
}

\author{
Jin Zhu* , Zijun Zhang, Tianjiao Hong \\ Environmental Art Design Department of Fashion \& Art Design College, Donghua University, Shanghai, China \\ Email address: \\ zhujindhu@foxmail.com (Jin Zhu),Jennifer_CZ@163.com (Zijun Zhang), 1020332496@qq.com (Tianjiao Hong) \\ ${ }^{*}$ Corresponding author
}

To cite this article:

Jin Zhu, Zijun Zhang, Tianjiao Hong. The Research of Co-design Approaches Based on Designer Guidance in the Renovation of Old Community in Shanghai- Illustrated in the Case of Zhuyuan Community Center. Landscape Architecture and Regional Planning.

Vol. 5, No. 3, 2020, pp. 55-60. doi: 10.11648/j.larp.20200503.12

Received: October 16, 2020; Accepted: October 26, 2020; Published: October 30, 2020

\begin{abstract}
With the decrease in usable land in recent years, people have begun to pay more attention to the renovation of small and micro space in old community space and discussion on urban space have gradually shifted from spatial to social attributes and social meanings. The demonstration of public participation process has been exactly being of significance on urban updating and adaptive reusing of existing stocks. Simultaneously, it has caused rethink about conventional designer-leading projects and enlightened academics about bottom-up concept for renovation. Nevertheless, the existing approaches of public participation is still facing certain issues such as imperfect participation mechanism, unclear-defined authorities and responsibilities, halfway involvement and so on. Through analyzing the renovation progress of the public space of Zhuyuan community, this article is aimed to argue whether the public might continuously and authentically participate to the holistic processes from preliminary design to construction and final operation based on multi-collaborations. And modular design approaches are experimented in order to integrate the variable resources, optimize the spatial functions and provide the ease of construction and assembly. Eventually, the public participation principles and strategies based on the guidance of designers are posed, which might provide a reference for the follow-up researches.
\end{abstract}

Keywords: Public Space, Participatory Design, Community Renovation, Modular Furniture

\section{Introduction}

Public participatory design in this article refers to plan or design attempting actively involving the public who are empowered and authorized for supervision and advising in the projects' design, complement and operation processes [1]. And the designer acts as the role of guidance instead of dominance. Feedbacks of the public might contribute to amendment of the sequent renovation results gradually. Community public space here refers to non-commercial but service-oriented interior and exterior space, where accommodates civilians' daily life and triggers events' occurring such as multi-functional micro space of community, activity center, pedestrian, small square and pocket park and so on. Consequently, the author poses the research question: How can designer-guiding approaches be integrated in public participation process and stimulate the aspiration and persistence for co-governance of the community?

\section{Feasibility and Case Analysis of Public Participation}

\subsection{Toolbox for Public Participation}

Basically, there are three types of participation methods used commonly and pervasively as follows: (1) workshop-based participation approach. And it means in interactive seminar, on one hand, designer inquires for the requirement of utilization, explain the relevant design process and demonstrate the design outcome to residents simotenously. On the other hand, the residents might communicate mutually. (2) Technical-oriented method based 
on information interaction. And that relies on the App (application program) for residents' participation, which results from the in-depth research of big data and provide the communication platform among government, society and public. (3) Crowd-funding method. As end user, every participant invests a small funds to the project and undertakes the due obligations in order to mastermind the scheme and makes contribution to the space.

Regarding motivations of the public, the participation degree might be discussed from three dimensions. And respectively, they are emotion, cognition and behavior. As the summary of the following table manifests, people with even different motivations might promote the spatial updating and construction in term of various aspects. Had emotional resonance been generated and cognition been emerged, the subconscious action or intentional behavior for multi-directional construction of the community could be sparked. (Table 1).

Table 1. Public participation motivation.

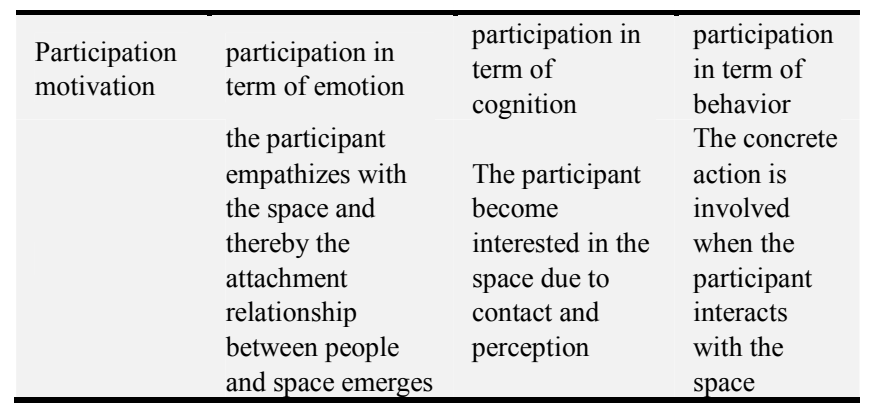

\subsection{Case Studies of Public Participation in Developed Countries, Developing Countries and Shanghai}

\subsubsection{Developed Countries}

Public participation in community planning was firstly started in the United Kingdom. And as a neighboring country, there is similar oriental culture background and high-density residential status in metropolises in Japan. Therefore, the following pilot projects are selected as references for holistic plan, capital source and rules of procedures. Since 1984, the updating of Coin Street Community in London South Bank was carried forward by CSCB (Coin Street Community Builders), which orientated itself as a social enterprise and all members must be the local habitants. With preferential cost of the land and other supports supplied by Greater London Council, it adopted non-profitable development-trust-fund operation pattern to transform the area from low-class neighborhood with underserved congest space to thriving mix used place. Before development approval was gotten, the consultation to public lasted for two years long. With the cooperation of residents, architects, social activists and well-known employers, the sequent "banding" renovation work altered the destiny of this area. As a result, the popularity there was raised, and neighborhood was congregated. Meanwhile, CSBS always kept maintaining the funds and paid off the load from bank and housing cooperation through commercial rentals $[4,5]$. The updating of Hanada community located in Adachi-ku of Tokyo had been proceeded block by block gradually depending on the marketing mechanism, support of the government and folk forces in order to activate the existing stocks, transfer their programs and vitalize the senescent living environment. The authorities of deliberation and management were committed to other organizations by the community updating associassion, which residents might participate to. They planted sakura in "Green Corridors", set rest areas in pocket squares, and designed the surrounding for houses.

\subsubsection{Developing Countries}

In less developed areas of the southern hemisphere, instead of sophisticated theories, some practical methods provided references in term of designer's guidance and operation models. In Chile, Architect Alejandro Aramean and his firm Elemental was committed to design "half a good house", which saved the preliminary invest and allowed the residents complete the rest portion. It experimented authentic participation way for "incremental" affordable housing for low-income family. Recent years he released the drawings of four typologies, which are available to the government, developers and public for open-source use [6-7]. In Kenya, as an organization consisting of members in interdisciplinary fields including urban plan, architecture, community, construction, finance and operation fields, KDI (Koonkie Design Initiative) have been "working with" (not "working for") local residents of an informal settlement called Kibera to transform unsafe and under-used sites into "Productive Public Spaces", address micro-scale issues, improve water and sanitary facilities and green infrastructures, generate income and catalyze community net-work [8]. For instance, they co-built sun-shade pavilion as a community center. And part of the proceeds from the crafts produced by Women's Weavers Cooperative called "Kiki Weavers" was used to maintain the funds operating.

\subsubsection{Communities in Shanghai}

Community constructing might be dominated by social organization, government, enterprise and specialist. Taking the case of the community in 669 lane Xinhua road as example, "Day Community Construction and Development Center" consisting of architects and sociological researchers took charge of contacting residents, neighborhood committees, designers and contractors through carrying out workshops, holding events etc. The previous janitor's room was redesigned as micro community center by this organization and other specialists might be involved in housing refurbishment, creation of other ambiences, facilities and signage system. In Yonghe Second Village in Pengpu town, residents were encouraged to take part in comprehensive community governance through establishing the social-operated platform called " $1+5+X$ meeting" and

\footnotetext{
1"1": General Secretary of the Community Party, "5": Community Director One Person, Community Police One Person, One Director of the Resident Property Committee, One Person in Charge of the Company, and person in charge of the mass team and social unit; " $X$ " includes the person in charge of the unit in the
} 
the decision-making platform called $" 3+1 "^{2}$. In Pudong communities, Nippon Paint once launched a project called "Colorful Community" in collaboration with worldwide artists in order to endear art to civilians. Renovation project of Tangqiao Leisure Plaza responded the appeal of "community micro-updating plan" advocated by the Planning and Land Resources Administration of Shanghai Municipality. After two-month long investigation rooted in this community, the academic group of experts and students posed and optimized the design of assembled stage transformed by flag-raising platform and scheme of pergola based on the residents' advices and feedbacks. It stimulated "community autonomy" altering from "social management". However, aspects such as communication procedure, enterprises' involving, financial resource are still confronting gaps [9].

\subsubsection{Summary}

To sum up, in developed countries the government, developer, non-government organization and residents might be relatively tightly bundled and corresponding integrated program could be implemented. While, in the background of social stratification of less developed countries, the spontaneously bottom-up practice might create equitable platform involving the voice of grassroots. And more efficient working procedure might be explored in order to make up the deficiency of the fund. After all, public participation and community autonomy have just been emerging as experimental measure in some metropoles of China, the dissimilitude of institution, non-practicable formalistic participation in especially implement process, the confliction between over construction and idle stocking are worthy of rethought.

\section{Case Study of the Design Process of Zhuyuan Community Center}

\subsection{Pre-design Phase}

\subsubsection{Recognition of Problems}

In open day the public participation workshop for Zhuyuan Community Center was organized in order to collect the residents' concrete feedbacks such as following: (1) Besides retaining the reading space and chess and card rooms, more activity spaces suitable for elderly should be extended. (2) The idle storage might be alternatively reused as other program. (3) The appointed system for reservation of multifunctional hall should be inserted. (4) The square might be preserved and the outdoor benches might be renovated as pergola with canopy and seats. (5) Some space was designed irrationally without consideration of ergonomics and details. For instance, the doors of toilets could not be closed conveniently (Figure $1^{3}$ ).

district, the leader of the building, party member volunteers, etc.

${ }^{2}$ Decision-making Hearings, Conflict Coordination Committee, Government council, and Mass Affairs Agency System built by the neighborhood committee.

3 Green means like, yellow means neutral and red means dissatisfied.

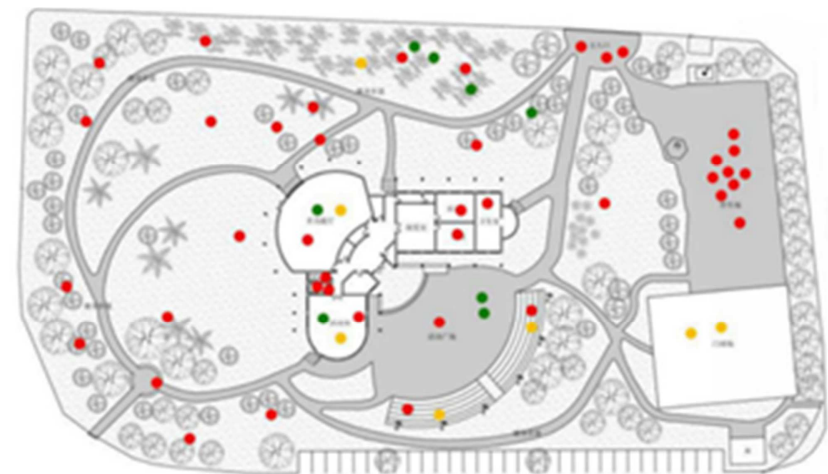

Figure 1. the spaces preserved and renovated based on the feedbacks of residents. Source: author's own photograph.

\subsubsection{The Functions Appealed by Residents}

(1) Appeal for more culture activities and meaningful communication events. Hence, market space and multifunctional hall for lecture, movie viewing and rehearsal might be concerned. The interactive space for parents and children was expected. Commuters hoped more realms would be explored for their interests and skills. (2) Appeal for more service. For instance, repair kiosk, barber shop and facilities for shareable umbrella should be added. (3) Appeal for commonweal. Used clothes might be donated in collectingpoints. And demonstration site for garbage classification should be set up.

\subsubsection{The Participation Status}

In one respect, majority of participants were just middle-aged and senior people. Due to lack of enthusiasm, instead of habitually being involved in discussions about public affairs in the short term, most of them would like to attend as observers of the events occurred. While, designers used to find out "universal" solutions or giving pervasive responds rather than figure out "specific" problems, which even might influence the judgements of residents.

\subsection{Initial Proposal Phase}

Synthesizing the outcome of preliminary survey and considering the interaction among people, as one of demonstrations through experimental furniture design in current phase, it focuses on how to stimulate residents to propose variable self-defined possibilities of the spatial utilization. Consequently, the corresponding strategies about movable modular furniture might provide opportunities for DIY (do it yourself) and changeable assembly and meanwhile save cost, reduce pollution of the site. Meanwhile the accuracy of the industrialized products might meet the trend of subtilized design.

As the table 2 shows, the neighborhood's living room and the tea area use the rail table which can be moved parallel, therefore residents can freely choose the location to rest, when the table is moved out in parallel, it provides the demand for drinking tea and communication between people; also, a full shielded and two types of semi-shielded sliding low coffee tables set there could be freely make users to enjoy a suitable reading space; the setting of multifunctional space 
is based on the needs of residents to hold some temporary activities, and the position of the partition wall can be changed according to different activities. The perforated board can be used to match the external modules, and the partition wall can also be folded to make it semi-enclosed; the dream classroom is mainly to create a family atmosphere, allowing people to share skills each other. The space will mainly be used in three ways, with a rotatable operation desk which can transform different functions as the center of the space (Table 2).

Table 2. Display of four modular furniture.

\begin{tabular}{l}
\hline $\begin{array}{l}\text { Four modular } \\
\text { furniture }\end{array}$ \\
\hline Rotating Cabinets \\
Multifunctional \\
Screen \\
Adjustable Display \\
Racks \\
Retractable Rail \\
Table
\end{tabular}

Another part is the integration of resources at the spatial level, reorganizing traffic routes in the space, so that the originally blocked space forms a loop. In the form of space, soft methods are used to divide the space. One is to use movable partitions, the other is to use grid-type partitions to allow related spaces to infiltrate and move each other; the third is to expand the window area and use french windows to make the indoor space. Actively interact with outdoor spaces to stimulate the possibility of residents participating in activities (Figure 2).
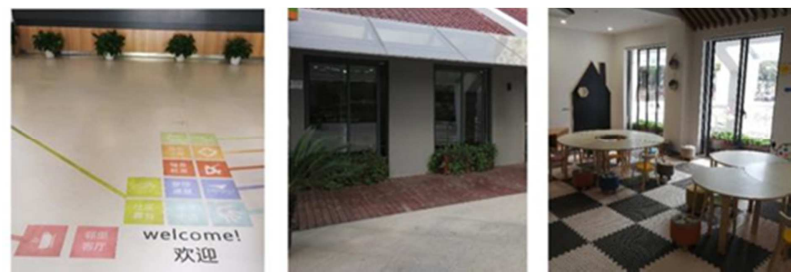

Figure 2. The state of the space put into use after the renovation.

\subsection{Analysis and Argument}

Conventional program of community updating with certain targets should be implemented depending on the commitments among clients, developers, consultants and contractors. And deliverable results are obliged. While, the space renovation involving public participation should satisfy the needs of living and the behavior of residents. Through continuous conversation with residents, the organization might define more definite assignments, pose more practical proposals and act correspondingly.

This section is about the spatial feasibility analysis and demonstration for the above design proposal. We gave our proposal to residents for post-evaluation, and after receiving the design plan, the residents expressed support and recognition for the neighborhood living room, fitness room and dream classroom. They believed that this proposal with open mechanism could realize the flexibility and transform the layout using modular furniture and movable partitions according to actual needs. A lonely elder in the community said that a well-designed neighborhood center could make her find the sense of a meaningless existence and self-identity, where might be the place for other elderly singletons friends of her. However, some interviewees confided their scruples. An elderly lady looking after grandkids said that it would be better if it could provide a baby-care room with a dining function. One young interviewee suggested to recruit merchants as the third party to settle in the community aiming to reinforce "self-hematopoiesis" function of the operators. For instance, vending machines and efficient barbers might be favored by young people.

In order to post-evaluate the design, this project collected 506 valid questionnaires to assess the popularity of four modular furniture designs. And SPSS is adopted to figure out the descriptive statistics. The analysis reveals that "Retractable Rail Table" is the biggest draws and 74\% residents vote it. "Rotating Cabinets" ranks in top 2 accounting for $59 \%$ and then $57 \%$ residents are in favor of "Adjustable Display Racks". "Multifunctional Screen" come in last accounting for $55 \%$. Thus it can be seen that the "Retractable Rail Table" and "Rotating Cabinet" are most favorable items among respondents surveyed. Certainly, it is just demonstration for test the post-evaluation design methodology, which maintains limitations on the optimization of the modular and processing technic. While, the feedbacks so far enlighten that the reliability, light operation, interoperability, manageability and esthetical appearance must be the crucial parameters effecting design thinking (Table 3).

Table 3. Post-evaluate descriptive statistics.

\begin{tabular}{llll}
\hline & N & Mean & Std. Deviation \\
\hline Retractable Rail Table & 506 & .74 & .438 \\
Multifunctional Screen & 506 & .55 & .498 \\
Adjustable Display Racks & 506 & .57 & .495 \\
Rotating Cabinets & 506 & .59 & .491 \\
Valid N (listwise) & 506 & & \\
\hline
\end{tabular}

In post-evaluation process of this project, it was found that the young and middle-aged people rarely participate in those activities held in neighborhood center, which causes lack of infusion of new blood. And there existed the phenomena of safeguarding rights blindly among elderly people. Everything does not happen at once and could not be accomplished in an action. Therefore, concept transformation needs long-term 
effort and promotion.

\section{Principles and Strategies of Public Participation Under the Guidance of Designers}

\subsection{The Participation Principle of Designer}

As professional design consultant, designer should control overall plan, organize the space and contribute to aesthetic quality. While, as the guider for the public, it is suggested that the abstract professional jargons and technique drawings should not be the preference for information dissemination. Simpler and more comprehensible expression might be more legible to common civilian. Instead of descending to just "technical servicer" dominated by the public, designer should be the bridge among all sectors of the society and simultaneously keep independent thinking and standpoint. As the collaborator, designer should give up the design authority partially and endow it to residents.

Generally speaking, conventional project needs relatively long-term procedure. Yet, once the designer shifts original role played from just professional to guider and collaborator as well, slight involvement might speed up the process of whole program and motivate residents themselves to address problems occurring in the community based on the limited existing resource. These spontaneous micro-updating network might be likened to acupuncture therapy to the community, which is mild but fast and efficient. The working scope of designer should not be restrained in the assignments and briefs. On the contrary, continuously improvised creation or solution might flexibly cope with outburst situation and establish a sensible space rather than follow rules with dogmatism or "academism" (Table 4).

Table 4. Three identities of designers participating in space creation.

\begin{tabular}{llll}
\hline & Professional & Guilder & Collaborator \\
\hline & site survey, & create communication & develop design \\
& social & interface, \\
& research, & platform, set & formulate \\
Specific & technique & discussion topic, & participation \\
Work & drawing, & summarize & plan of \\
Content & materials & suggestions of all & residents, \\
& selection, & sectors, propose & redesign, \\
& supervising & corresponding scheme & develop and \\
& construction & and solution & optimize scheme \\
\hline
\end{tabular}

\subsection{The Participation Approaches of Designer}

Three sequent steps are required for designers in project process.

\subsubsection{Observation and Record}

Through this sort of typical empirical method, designer might understand the categories, forms, contents of individual activities and mass incidents, which might trigger concrete images and perceptual intuition. And relevant original data should be recorded such as photograph, video, sketch and script. Meanwhile, spatial issues and the factors effecting cohesiveness of the community might be discovered.

\subsubsection{Communication}

First of all, designer should dwell on the aim, significance and process of participation to let residents understand community is common home of everyone. Requirements for physical space must be necessary certainly. Secondly, more chitchatting related to daily life might be more impersonal than leading questions with subjective gentle hints. For instance, we should use "Do you usually take kids to play in the community?" and "What kind of activities do children like?" instead of "What do you think of this space?" or "Do you think it would be a good idea to add such a facility here?". Thirdly, the conversion should be publicly open to all participants so that they might understand the opinions mutually and initiate more ideas. Moreover, the scheme should be presented with more visual language and other concrete means such as little simple spatial experiment, which might reflect the real reactions of residents in term of physiology, behavioristics and psychology.

Besides, incentive mechanism should be considered. For instance bounty or other benefits should be offered to residents who contribute more to community construction. Only then will it be possible that more participants serve for public as well as help themselves. For another example, as long as the holistic environment and atmosphere improved, the average rental of some compounds located in commercial or tourism area might be increased and consequently the households would be able to realize higher revenue. After all, all participants are stakeholders. The requirements and related suggestions especially about incentive payment should be collected by pooling the wisdom and efforts of everyone. Interview, questionnaire are pervasive and efficient platform-build tools. Most importantly, mutual trust might not be built before communication in person time and again.

\subsubsection{Collaboration}

This is the key step that residents-based and service-oriented participation transforms to authentic co-design, which allows the amateur design with professionals together. In the open process, design group devotes itself to coordinating work mostly so that the operation mode with more social concern and higher efficiency might be explored.

\section{Conclusion}

Starting from the perspective of public participation, this paper takes domestic and foreign cases as references and analyzes the role designer plays and corresponding working process and approaches illustrated in the renovation case of Zhuyuan Community Neighborhood Center. Eventually, the conclusion is drawn as follows: (1) synergetic development is the trendy pattern of community updating, which stimulates the residents' autonomy integrating with the efforts of the government, designer, social organization and media. (2) The role of the designer 
alter from service-oriented professional to collaborator or coordinator, who is required to guild the residents self-building spontaneously with expertise supporting and the ability of reconciling and moderating. They might react fast but continuously according to the limited budget, aged facility, small area and the "shock" caused by the lack of aesthetic sensitivity of some common grassroots. (3) The participation process should be open to all and more participants in different ages should be involved in. (4) Modular design concept might provide various options for self-defined multifunction based on residents' life experience and meanwhile satisfy he subtilized design trend.

Due to the limitation of quantitative analysis and imperfection of periodic outcome caused by partially demonstration work about design and post-evaluation, some defectiveness still surrounds findings. In the subsequent research after all areas are designed, there must be focuses as follows. Firstly, the participation ways of residents in different ages, incomes, education levels and backgrounds might be discrepant, which should be subdivide, argued and verified. Secondly, elaborated study of the categories and hierarchies of self-building abilities of residents should be carried out so that the guidebook for their autonomic construction could be proposed as authentic specific support, which might include not only the consulting of users' requirements in preliminary phase but also public participation in further design, construction and operation phases.

\section{References}

[1] Trischler, Jakob; Pervan, Simon J.; Kelly, Stephen J.; Scott, Don R. (2018). "The Value of Codesign". Journal of Service Research. 21: 75-100. doi: 10.1177/1094670517714060.

[2] Pieters, Maarten; Jansen, Stefanie (2017). The 7 Principles of Complete Co-creation. Amsterdam: BIS Publishers. p. 15. ISBN 978-90-6369-473-9.

[3] Li zhi (2013). Tianzifang: a bottom-up sustainable old city renewal model. China: Fujian Architecture. 86-88+82. ISBN $1000-114 x$.

[4] Yang Siqin (2016). Coin Street: The best example of community building to promote urban renewal. http://www.participation.cn/xinwenzixun/guojidongtai/19797. html.

[5] Andrew Bibby (2009). Coin Street - case study.http://www.andrewbibby.com/socialenterprise/coin-stre et.html.

[6] Kaley Overstreet (2016). Alejandro Aravena's Downloadable Housing Plans and the Real Meaning of "Open-Source Urbanism". https://www.archdaily.com/788524.

[7] Jenna McKnight (2016). Alejandro Aravena makes housing designs available to the public for free.https://www.dezeen.com/2016/04/06/alejandro-aravena-e lemental-social-housing-designs-architecture-open-source-pri tzker.

[8] kounkuey: 2017.https://www.kounkuey.org/about.

[9] Xu Leiqing (2018) Planning Practice of Tangqiao Community from the Perspective of Social Governance. https://mp.weixin.qq.com/s?_biz=MzA4NDA3NzgzOA==\& $\mathrm{mid}=2681730557 \& \mathrm{idx}=1 \& \mathrm{sn}=2 \mathrm{bfaa} 830 \mathrm{cc} 152 \mathrm{e} 44853759 \mathrm{e} 41$ acc7e9a\&chksmect.

[10] 2018. The reply of the State Council on the Overall Urban Planning of Shanghai, Town Planning Newsletter.

[11] Xu Zhongzheng (2000). Review and prospect of Community construction in Shanghai, Shanghai University Press.

[12] Xu Minghong (2013). Study on the effectiveness of urban residents' community participation, Shanghai Jiao Tong University.

[13] Wangle Puqin (2015). Research on public participation and community satisfaction-Taking the comprehensive survey of shanghai community as an example, Tongji University Community Research, Shanghai Community Research and Planning

[14] Hong Tianjiao (2019). Research on public space constructing strategies of shanghai old community based on public participation, Donghua University.

[15] Shen yao, Yang yan, Mu Xia yong, Xu Meng yi (2018). Theoretical analysis of participatory design in the context of community design and research on sustainable operation mode, Architecture Journal.

[16] Shen Aobo, Liu Jiayan, Shen Yichen (2018). Experience and characteristics of the old Japanese communities-the case study of two communities in Tokyo, Shanghai City Planning.

[17] Putnam, R (1993). Making democracy work: civil tradition in modern Italy, Princeton university press.

[18] Cao Zheng (2019). Study on community renewal strategy based on the concept of sharing, Beijing University of Civil Engineering and Architecture.

[19] Dong Liqin (2019). Discuss the reuse of idle space in old community, Building Environment Science and Engineering. 